\title{
Desarticulación del planeamiento estratégico y la programación presupuestaria y su efecto en la gestión del CEPLANi
}

\section{Disarticulation of strategic planning and budget programming and its effect on CEPLAN management}

\author{
Elmer Marcos Galloso Porras ${ }^{2}$ \\ Universidad Nacional Mayor de San Marcos \\ marcosgalloso@hotmail.com \\ Juan José Ospino Edery ${ }^{3}$ \\ Universidad Nacional Mayor de San Marcos \\ jospino@unmsm.edu.pe
}

Recibido: 23/07/2020 - Aceptado: 29/12/2020 - Publicado: 17/02/2021

\begin{abstract}
RESUMEN
La administración pública en Perú se desarrolla a través de la interrelación dinámica de los distintos sistemas administrativos, los mismos que están constituidos por principios, normas, procedimientos, técnicas e instrumentos que les permiten desarrollar sus actividades permanentes en función de las personas y de la sociedad. Todos los sistemas administrativos, de una forma u otra, están vinculados; entre ellos, se destaca la vinculación entre los Sistemas de Planeamiento Estratégico y de Presupuesto Público, por cuanto el primero establece el tipo de sociedad que se quiere lograr y el segundo es la expresión financiera que permite asignar los recursos públicos en función de los resultados a obtener. En el presente artículo se ha analizado cómo se ha dado la vinculación de dichos sistemas en el Centro Nacional
\end{abstract}

(C) Los autores. Este artículo es publicado por Pensamiento Crítico de la Facultad de Ciencias Económicas, Universidad Nacional Mayor de San Marcos. Este es un artículo de acceso abierto, distribuido bajo los términos de la licencia Creative Commons Atribucion - No Comercia_Compartir Igual 4.0 Internacional. (http://creativecommons.org/licenses/by-nc-sa/4.0/) que permite el uso no comercial, distribución y reproducción en cualquier medio, siempre que la obra original sea debidamente citada. 
de Planeamiento Estratégico (CEPLAN) en el periodo 2009-2018 y cómo ha influido en el logro de los objetivos de la entidad. La principal conclusión que se ha obtenido es que la desarticulación entre los sistemas de planeamiento estratégico y la programación de gastos ha tenido un efecto negativo en la gestión del CEPLAN.

Palabras clave: Planeamiento estratégico; presupuesto público; gestión pública. JEL: H, H6, H61.

\section{ABSTRACT}

The public administration in Peru is developed through the dynamic interrelation of the different administrative systems, which are constituted by principles, norms, procedures, techniques and instruments that allow them to develop their permanent activities based on people and society. All administrative systems, in one way or another, are linked; Among them, the link between the Strategic Planning and Public Budget Systems stands out, since the first establishes the type of society to be achieved and the second is the financial expression that allows the allocation of public resources based on the results to obtain. This article has analyzed how these systems were linked in the National Center for Strategic Planning (CEPLAN) in the 2009-2018 period and how it has influenced the achievement of the entity's objectives. The main conclusion that has been obtained is that the disarticulation between the strategic planning systems and the programming of expenses has had a negative effect on the management of CEPLAN.

Keywords: Strategic planning; public budget; public management.

JEL: H, H6, H61. 


\section{Introducción}

La planificación estratégica puede ser analizada desde dos perspectivas: como proceso o como resultado. Si se la considera como proceso, consiste en un ejercicio de carácter intelectual mediante el que, a partir del diagnóstico situacional de un país, de una región o de una organización se determinan los objetivos de carácter prioritario a lograr y los cursos de acción para la consecución de los objetivos en horizontes temporales de mediano y largo plazo. Si es analizada como resultado, permite adoptar decisiones, teniendo en cuenta tanto el entorno de la organización, país o región como los posibles futuros que podrían presentarse con el propósito de incrementar las fortalezas, aprovechar eficientemente las oportunidades, reducir el impacto de las amenazas y minimizar las debilidades (Armijo, 2009).

En el contexto del proceso de suscripción del Tratado de Libre Comercio Perú - Estados Unidos, se suscribió el 22 de julio de 2002 el Acuerdo Nacional $^{4}$, a través del cual se estableció como quinta política de Estado, dentro del primer objetivo "Fortalecimiento de la Democracia y Estado de Derecho", la siguiente: "Gobierno en función de objetivos y con planeamiento estratégico, prospectiva nacional y procedimientos transparentes". Con el propósito de materializar dicho enunciado, mediante la Ley $\mathrm{N}^{\circ} 28522$, se crearon el Sistema Nacional de Planeamiento Estratégico y el Centro Nacional de Planeamiento Estratégico (CEPLAN); dicha norma legal fue derogada por el Decreto Legislativo $N^{\circ} 1088$ con el propósito de facilitar la aplicación del mencionado Tratado de Libre Comercio. En el numeral 5.1 de este dispositivo legal se definió al CEPLAN como "el organismo técnico especializado que ejerce [a nivel nacional, comentario del autor] la función de órgano rector, orientador y coordinador del Sistema Nacional de Planificación".

El CEPLAN es una entidad adscrita a la Presidencia del Consejo de Ministros (PCM) y constituye un pliego presupuestario. De acuerdo a sus funciones, le corresponde formular e implementar, en el ámbito de su competencia, las políticas nacionales a través de sus propios documentos de gestión institucional como son: Plan Estratégico Institucional (PEI), Plan Operativo Institucional (POI), Presupuesto Institucional de Apertura (PIA), Reglamento de Organización y Funciones (ROF) y Manual de Organización y Funciones (MOF). 
En el aspecto del planeamiento estratégico, cabe señalar que mediante la Resolución Ministerial № 289-2015-PCM se aprobó el Plan Estratégico Sectorial Multianual (PESEM) 2016-2020 de la PCM. En el marco de este documento, el CEPLAN estableció seis objetivos estratégicos institucionales (OEI), los cuales se articularon con dos objetivos del mencionado PESEM de la PCM: "Mejorar la coordinación multisectorial y multinivel para la adecuada gestión de las políticas nacionales" y "Mejorar la implementación de la gestión pública para resultados en todas las entidades públicas". En la Tabla 1, se muestra la articulación de los objetivos estratégicos institucionales del CEPLAN con los objetivos estratégicos sectoriales de la PCM.

Tabla 1

Articulación de los objetivos estratégicos institucionales del CEPLAN con los objetivos estratégicos sectoriales de la Presidencia del Consejo de Ministros.

\begin{tabular}{|c|c|}
\hline Objetivo Estrategico Sectorial.01 & $\begin{array}{l}\text { Mejorar la coordinación multisectorial y multinivel para la } \\
\text { adecuada gestión de las políticas nacionales }\end{array}$ \\
\hline Objetivo Estrategico Institucional.01 & $\begin{array}{l}\text { Conducir el proceso de formulación y difusión de la visión } \\
\text { concertada de futuro del Perú }\end{array}$ \\
\hline Objetivo Estrategico Institucional.02 & $\begin{array}{l}\text { Generar información acerca de tendencias, escenarios, variables } \\
\text { estratégicas y alertas tempranas }\end{array}$ \\
\hline Objetivo Estrategico Institucional.05 & $\begin{array}{l}\text { Generar y actualizar de forma permanente la información para el } \\
\text { conocimiento integral de la realidad del territorio }\end{array}$ \\
\hline Objetivo Estrategico Sectorial.03 & $\begin{array}{l}\text { Mejorar la implementación de la gestión pública para resulta- } \\
\text { dos en todas las entidades públicas }\end{array}$ \\
\hline Objetivo Estrategico Institucional.03 & $\begin{array}{l}\text { Asesorar a las entidades del Estado y Gobiernos Regionales en la } \\
\text { elaboración de políticas y planes }\end{array}$ \\
\hline Objetivo Estrategico Institucional.04 & $\begin{array}{l}\text { Orientar en la elaboración de políticas y planes a los Gobiernos } \\
\text { Locales, Provinciales y Distritales }\end{array}$ \\
\hline Objetivo Estrategico Institucional.06 & $\begin{array}{l}\text { Realizar el seguimiento y evaluación de la gestión estratégicas del } \\
\text { Estado }\end{array}$ \\
\hline
\end{tabular}

Fuente: Plan Estratégico Institucional del CEPLAN. Elaboración propia.

En el aspecto presupuestal, el CEPLAN ha sido financiado exclusivamente por la fuente de financiamiento denominada recursos ordinarios ${ }^{5}$. El monto asignado en las diversas leyes anuales de presupuesto, en el periodo 2009 - 2018, ha presentado una tendencia creciente alcanzando sus picos más altos en los años fiscales 2016 y 2017. En la Figura 1, se muestra la evolución del crédito presupuestario asignado en el período 2009-2018. 


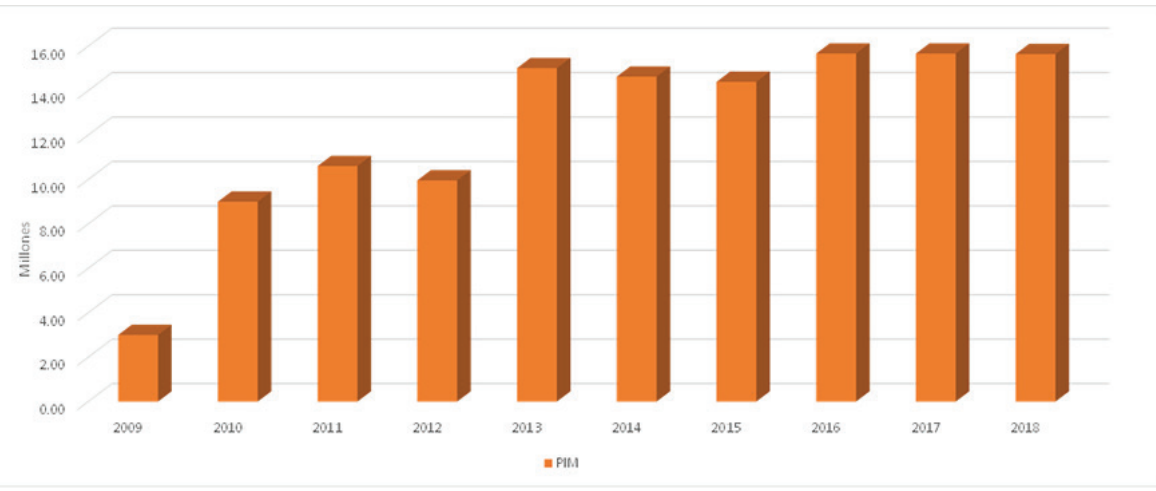

Figura 1. Evolución del presupuesto institucional modificado del CEPLAN. Periodo 2009-2018.

Fuente. Sistema Administrativo Financiero - SIAF. Elaboración propia

Teniendo en consideración lo expuesto, se formuló como problema principal de la investigación: ¿Cuál es el efecto de la desarticulación entre el sistema de planeamiento estratégico y la programación presupuestaria en la gestión pública del CEPLAN? y como problemas específicos: (i) ¿Qué efecto tiene el POI en la gestión pública del CEPLAN? y (ii) ¿En qué medida la programación presupuestaria de gastos incide en la gestión pública del CEPLAN?

En consecuencia, el objetivo general que se previó alcanzar fue: Determinar el efecto de la desarticulación entre el sistema de planeamiento estratégico y la programación presupuestaria en la gestión pública del CEPLAN y como objetivos específicos: (i) Determinar el efecto del POI sobre la gestión pública del CEPLAN y (ii) Determinar en qué medida la programación presupuestaria de gastos incide en la gestión pública del CEPLAN.

\section{Metodología}

\subsection{Tipo y diseño de la investigación.}

El tipo de investigación ha sido no experimental (ex post facto) puesto que no se han variado intencionalmente las variables dependientes, sino que se ha observado el fenómeno tal y como se dio en su contexto natural para 
después someterlo al análisis correspondiente. Es decir, se han hecho inferencias sobre la relación entre las variables sin intervención directa sobre dichas variables. Hernández, Fernández y Baptista (2010, p. 149) la definen como:

...la investigación que se realiza sin manipular deliberadamente variables. Es decir, se trata de estudios donde no hacemos variar en forma intencional las variables independientes para ver sus efectos sobre otras variables. Lo que hacemos en la investigación no experimental es observar fenómenos tal como se dan en su contexto natural, para posteriormente analizarlos.

La investigación ha buscado hallar la explicación de la influencia de la vinculación entre la planificación estratégica y el proceso presupuestario público en la conducción del CEPLAN, utilizando previamente las experiencias laborales adquiridas por el autor en instituciones y organizaciones públicas a fin de centrar el análisis en dicha problemática y contribuir al beneficio de la sociedad.

Asimismo, Hernández et al. (2010, p. 158) describieron el concepto de diseños longitudinales en los términos siguientes.

En ocasiones el interés del investigador es analizar cambios a través del tiempo de determinadas categorías, conceptos, sucesos, variables o comunidades; o bien, de las relaciones entre éstas. Aun más, a veces ambos tipos de cambios. Entonces disponemos de los diseños longitudinales, los cuales recolectan datos a través del tiempo en puntos o períodos, para hacer inferencias respecto al cambio, sus determinantes y consecuencias.

Por ello, en el marco de esta descripción, es que se eligió para el desarrollo de la investigación el diseño de investigación longitudinal por cuanto se ha analizado en qué medida la vinculación entre dos constructos: Sistema Nacional de Planeamiento Estratégico y Sistema Nacional de Presupuesto en un periodo de tiempo determinado 2009 - 2018 ha influido en la gestión del CEPLAN. Las áreas de planeamiento estratégico, el área de proceso presupuestario y la gestión del CEPLAN durante el periodo 2009-2018 se constituyeron como unidades de análisis. 
Se seleccionó el CEPLAN porque en el marco de lo establecido en el Artículo10.3 de la Ley del Sistema Nacional de Planeamiento Estratégico y del Centro Nacional de Planeamiento Estratégico, Decreto Legislativo $\mathrm{N}^{\circ}$ 1088, una de sus funciones es:

Asesorar a las Entidades del Estado y a los gobiernos regionales y orientar a los gobiernos locales en la formulación, el seguimiento y la evaluación de políticas y planes estratégicos de desarrollo, con la finalidad de lograr que se ajusten a los objetivos estratégicos de desarrollo nacional previstos en el Plan Estratégico de Desarrollo Nacional.

Se han recopilado datos principalmente de segundo nivel, relacionados a información de planificación estratégica y del proceso de presupuesto público del CEPLAN y se ha utilizado la técnica de la estadística inferencial para la verificación de las hipótesis; la cual, ha permitido establecer si se ha verificado la hipótesis formulada a partir del desarrollo del modelo de regresión propuesto. Para ello se ha utilizado el aplicativo estadístico Econometric Views (EViews), conforme al siguiente modelo:

$$
G P C=c+b^{*} D E S
$$

Donde:

GPC: Gestión del CEPLAN

c y b: Parámetros del modelo

DES: Desarticulación del planeamiento estratégico y proceso presupuestario.

\subsection{Hipótesis general e hipótesis específicas}

La hipótesis general que se formuló y orientó el desarrollo de la investigación fue: La desarticulación entre el sistema de planeamiento estratégico y la programación presupuestaria incide en la gestión pública del CEPLAN y como hipótesis específicas: (i) El POI incide en la gestión pública del CEPLAN y (ii) La programación presupuestaria de gastos incide en la gestión pública del CEPLAN. 


\subsection{Identificación, definición conceptual y operacionalización de las variables de la hipótesis general}

\subsubsection{Variable independiente (X): Planificación estratégica (PE) - Proceso presupuestario (PP)}

La planificación estratégica es definida como la determinación de los objetivos y las acciones estratégicas y las actividades operativas para lograr los efectos esperados por una entidad, que en este caso es de carácter estatal. El complimiento de lo expuesto se materializa en el presupuesto institucional modificado (PIM) que ha tenido el CEPLAN durante los ejercicios fiscales señalados.

$$
\text { Variable X } \longrightarrow \text { Vinculación Plan - Presupuesto }
$$

La vinculación entre el plan y presupuesto es un proceso sinérgico que se desarrolla en diferentes etapas que permiten el establecimiento y ejecución de políticas públicas en una determinada entidad pública; en el presente caso, el CEPLAN.

\subsubsection{Variable dependiente (Y): Gestión pública del CEPLAN (GPC)}

Es la variable que describe el desarrollo eficiente de la actividad esencial y que define al CEPLAN: órgano rector, orientador y de coordinación del SINAPLAN. El indicador de desempeño es una herramienta de evaluación que proporciona resultados cuantitativos sobre la consecución de los logros de una entidad en beneficio de la sociedad, conforme al marco de sus objetivos priorizado y su razón de ser. Es expresado, de manera general, en un índice porcentual de desempeño.

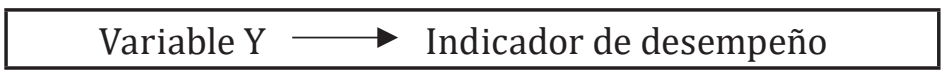

2.4. Identificación, definición conceptual y operacionalización de las variables de las hipótesis específicas

\subsubsection{Hipótesis Específica 1}

Variable independiente $\left(\mathrm{X}_{1}\right)$ : Plan Operativo Institucional (POI).

Es el conjunto de actividades operativas necesarias que prevé realizar la entidad con el propósito de alcanzar los objetivos estratégicos 
determinados por la más alta autoridad administrativa. En ese sentido, la variable de medición está constituida por el avance de las metas operativas con respecto a las actividades programadas del POI. Es la generación de recursos y servicios que la entidad pública programa para un determinado año fiscal desarrollándose de acuerdo con sus funciones; son permanentes y continuas en el tiempo; responden a objetivos priorizados que pueden ser medidos cualitativa o cuantitativamente.

$$
\text { Variable X1 } \longrightarrow \text { Actividades operativas }
$$

\section{Variable dependiente (X3): Gestión del CEPLAN (GPC).}

Es la que describe el desarrollo eficiente de sus funciones establecidas en el artículo 10.3 del Decreto Legislativo $\mathrm{N}^{\circ} 1088$ citado anteriormente.

El indicador de desempeño es una herramienta de evaluación que proporciona resultados cuantificables sobre la consecución de los logros de una entidad en beneficio de la sociedad, conforme al marco de sus objetivos priorizados y su razón de ser. Es expresado, de manera general, en un índice porcentual de desempeño.

$$
\text { Variable X3 } \longrightarrow \text { Indicador de desempeño }
$$

\subsubsection{Hipótesis Específica 2}

\section{Variable independiente $\left(\mathrm{X}_{2}\right)$ : Proyección de gastos (PG).}

Es la previsión de gasto en el corto plazo de una entidad con la finalidad de lograr las metas previstas para la obtención de los efectos esperados por la entidad. Es un proceso donde se analizan y evalúan las previsiones de gasto para el cumplimiento de los objetivos y metas de corto plazo (un año) en una determinada entidad pública.

$$
\text { Variable X2 } \longrightarrow \text { Proyección de gasto }
$$

\section{Variable dependiente (X3): Gestión del CEPLAN (GPC).}

Es la variable que describe el desarrollo eficiente de sus actividades para cumplir con las funciones establecidas en el artículo 10.3 del Decreto Legislativo $\mathrm{N}^{\circ} 1088$, citado anteriormente. 
La interrelación de las variables se representa esquemáticamente en la Figura 2 Modelo de la interrelación de variables.

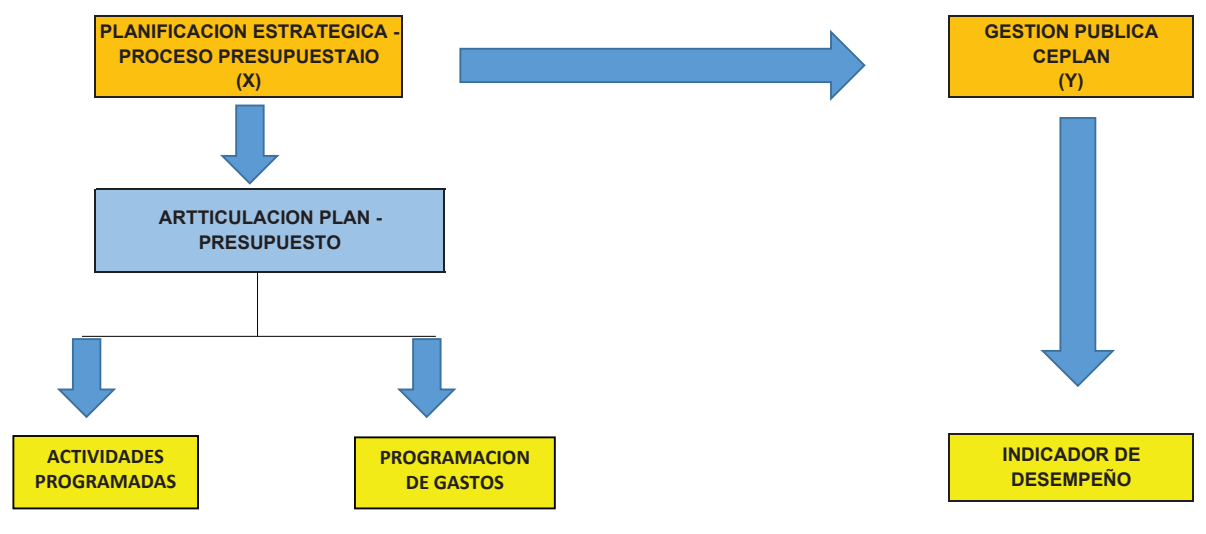

Figura 2. Modelo de la interrelación de variables.

Fuente: Elaboración propia.

\section{Marco teórico}

\subsection{Antecedentes del problema.}

Se establecieron a partir de la búsqueda bibliográfica de investigaciones atingentes al tema realizadas en el país y de documentos elaborados por expertos que cumplen importantes funciones en organismos internacionales o multilaterales.

Las investigaciones realizadas a nivel nacional, como se expondrá, han tomado diversas unidades de análisis tales como organismos públicos constitucionalmente autónomos -caso Defensoría del Pueblo-, las municipalidades y ministerios. Así se tiene, la tesis de Neyra (2012, p.124) "El planeamiento y el presupuesto público y su influencia en la gestión pública. Caso Defensoría del Pueblo, período 2000-2010", en la que planteó las siguientes conclusiones:

(i) la Planificación y el Presupuesto Público integrados influyen positivamente en la gestión pública de la Defensoría del Pueblo. (ii) El proceso de planificación con estrategias definidas y una programación especificada y direccionada a alcanzar los objetivos esperados 
y los recursos presupuestales que permitan llevarla a cabo, influenciará favorablemente en la gestión de la Defensoría del Pueblo.

La tesis elaborada por Prieto (2012, p.122): "Influencia de la gestión del presupuesto por resultados en la calidad del gasto en las municipalidades del Perú (2006-2010). Casos: Lima, Junín y Ancash" en la que la principal conclusión fue "La aplicación del Presupuesto por Resultados en las municipalidades del Perú mejora la calidad del gasto público ya que ellos son destinados a favorecer los niveles de vida de la población". Finalmente, la tesis de Tanaka (2011, p.126): "Influencia del presupuesto por resultados en la gestión financiera presupuestal del Ministerio de Salud" en la que una de sus conclusiones fue que en el Ministerio de Salud "se observa una débil articulación del planeamiento con el presupuesto desde una perspectiva de resultados".

Entre los segundos, se puede señalar a Armijo (2009, p.113), quien por encargo del Instituto Latinoamericano de Planificación Económica y Social (ILPES), órgano integrante de la Comisión Económica para América Latina y el Caribe (CEPAL), elaboró el documento "Planificación estratégica e indicadores de desempeño en el sector público" y sostuvo que una visión estratégica de país trasciende a un plan de gobierno; con relación a la vinculación entre la planificación estratégica y la programación presupuestaria, el mencionado autor estableció que era necesario determinar los impactos que dicha vinculación tendría sobre la población: "El carácter estratégico de la planificación y programación presupuestaria establece un procedimiento normado y con una metodología orientada al desarrollo de indicadores en toda la fase del proceso productivo con énfasis en la determinación de los impactos". La aplicación de este proceso técnico y metodológico permitirá superar, lo que se ha venido en llamar, la metodología incrementalista que prioriza los insumos por encima de los resultados e impacto de estos en la población beneficiada.

Tavares y Berretta (2006), en el informe preparado para el Banco Interamericano de Desarrollo (BID) titulado "Sistemas de planificación estratégica e innovaciones presupuestarias" y, posteriormente, Marcel, Guzmán y Sanginés (2014) en una investigación realizada por encargo del Banco Interamericano de Desarrollo (BID) titulada "Presupuestos para el desarrollo de América Latina” establecieron que el presupuesto público 
tiene que hacer frente a múltiples factores externos, diversidad de intereses y de organizaciones ubicadas en diferentes niveles de gobierno (nacional, regional y local) y cambios económicos no previstos; y todo esto conllevó a considerar el presupuesto como un medio esencial de gestión macroeconómica y de planificación.

Por su lado, Shack (2008), en el documento de trabajo denominado "Intentando caracterizar la articulación entre el plan y el presupuesto. Algunas experiencias en América Latina" preparado para el BID, concluyó que para que haya una mejora significativa y sostenible a mediano plazo del proceso de integración de plan y presupuesto se deberían construir metodologías más robustas, sistemas más integrados y fortalecer capacidades en todos los operadores públicos relacionados con la gestión. Shack (2014, p.142), en otro documento titulado "La articulación entre el plan y el presupuesto: un tema recurrente en el trabajo del ILPES en la región” incluido en una publicación de la CEPAL, concluyó, en los términos siguientes, que dos aspectos son fundamentales y necesarios para que el proceso de integración entre planeamiento estratégico y presupuestación en el sector público sea un éxito:

(i) Un apropiado arreglo institucional que vaya más allá de establecer ciertas reglas formales, roles de actores y estructuras organizacionales, y que se tengan en cuenta las relaciones informales y los procesos de trabajo con los que cotidianamente opera la administración burocrática, y (ii) un mínimo de capacidades técnicas, en el sentido, no solo de disponer de personal calificado en las áreas de planificación, presupuesto y gestión, y contar con sistemas administrativos que se caractericen por su rigor metodológico y su flexibilidad de aplicación, sino también de tener sistemas de información que, usados por los actores en forma apropiada, permitan efectivamente un mejor proceso de toma de decisiones.

Tavares y Berretta (2009) en un documento titulado "Sistemas de planificación estratégica e innovaciones presupuestarias" realizaron un estudio con el objetivo de estudiar y proponer las posibilidades de profundizar la vinculación y articulación entre el planeamiento estratégico y el presupuesto; es decir, entre lo deseado y lo posible. La investigación analizó las experiencias llevadas a cabo en Brasil, Colombia, Guatemala, 
México y Uruguay y establecieron algunas dificultades que confrontó la vinculación del planeamiento estratégico con el presupuesto: las estructuras institucionales eran obsoletas y entorpecían dicho proceso; la falta de sincronía entre los procesos de liberalismo económico y de liberalismo político; la vinculación sinérgica entre ambos sistemas se diluye en la ejecución tanto de los planes como de los presupuestos; la recuperación de la inversión social no estuvo acompañada de un crecimiento en el ámbito de la infraestructura. Al respecto, Marcel et al. (2014) establecieron que una característica frecuente en América del Sur es la poca colaboración entre las áreas de planificación y presupuesto.

\subsection{Planeamiento estratégico.}

Guerra-García (2001) señaló que, en el Perú, históricamente, los procesos de planificación, programación y presupuestación han estado desvinculados y que, a esa fecha, no se había superado tal situación. Señaló que la planificación se basa en tres principios que están estrechamente vinculados con la presupuestación y son:

(i) La planificación se orienta a visualizar situaciones futuras y a conectar las decisiones presentes para organizar una situación futura deseada.

(ii) La planificación es holística, prevé el uso de todos los recursos.

(iii)La planificación vincula los medios a los objetivos que se quieren alcanzar.

Según lo establecido en el Capítulo I (artículo 6) de la "Directiva para la actualización del Plan Estratégico de Desarrollo Nacional" (CEPLAN, 2017), el ciclo de planeamiento estratégico para la mejora continua este compuesto por cuatro fases que son: "Fase 1: Conocimiento integral de la realidad". "Fase 2: El futuro deseado". "Fase 3: Políticas y planes coordinados". "Fase 4: El seguimiento y la evaluación de políticas y planes para la mejora continua".

Según Granados, Larraín y Rodríguez (2009), la importancia de la planificación estratégica y la necesidad de relacionarla de forma adecuada con el proceso presupuestario ha sido un tema altamente debatido en las últimas décadas. En esa dirección, la asignación de recursos en un plan 
estratégico de largo plazo debe de considerar las restricciones presupuestarias existentes, de lo contrario, se traducirá en un plan poco probable de llevarse a cabo.

\subsection{Presupuesto público}

Se estima conveniente iniciar el desarrollo de este subtítulo señalando la definición que, desde un punto de vista legal, orienta el desarrollo del presente artículo. Según el numeral 13.1 del Decreto Legislativo del Sistema Nacional de Presupuesto Público, Decreto Legislativo $N^{\circ} 1440$ :

El presupuesto constituye el instrumento de gestión del Estado para el logro de resultados a favor de la población, a través de la prestación de servicios y logro de metas de coberturas con eficacia y eficiencia por parte de las entidades. Asimismo, es la expresión cuantificada, conjunta y sistemática de los gastos a atender durante el año fiscal, por cada una de las entidades del sector público y refleja los ingresos que financian dichos gastos.

Dicha definición se complementa con lo que estableció Mena (2004) que el presupuesto es un instrumento de planificación anual que ayuda en la priorización de las demandas de la ciudad. Se trata de un espacio de cogestión en el que la comunidad y el gobierno deciden conjuntamente sobre el destino de las inversiones.

Es de señalar que la metodología de la programación y formulación del presupuesto público, tanto a nivel internacional como a nivel nacional, ha tenido una evolución. Es en Estados Unidos de Norteamérica en 1965 que se introdujo la metodología de Presupuesto por Programas (PPBS ${ }^{6}$, por sus siglas en inglés y PpP como sigla en español), (Neyra, 2012) y en 1970 se adoptó la metodología de Presupuesto Base Cero (Alvarado y Morón, 2008).

A pesar de los esfuerzos innovadores, la programación y formulación presupuestaria desde los inicios del siglo pasado hasta los inicios de la década del noventa dieron como resultado un presupuesto por insumos; es decir, un presupuesto esencialmente incrementalista. En cada ejercicio presupuestal se fijaba una cantidad adicional sobre la base de lo asignado en el ejercicio presupuestal anterior. Muy posteriormente, 
y ya en el presente siglo, en cumplimiento de lo establecido en el Capítulo IV de la Ley de Presupuesto del Sector Público para el Año Fiscal 2007, Ley $N^{\circ} 28927$, se inició, en forma paulatina, la implementación de la técnica metodológica del presupuesto por resultados (PpR); la misma que, según el portal del Ministerio de Economía y Finanzas del Perú, es definida como "una estrategia de gestión pública que permite vincular la asignación de recursos presupuestales a bienes y servicios (productos) y a resultados a favor de la población". Esta sencilla definición demanda: presencia de objetivos claros y previamente establecidos; compromiso de alcanzar el objetivo principal frente a otros a objetivos de menor importancia; identificación de responsables; implementación de sistemas de evaluación de efectos y de obtención de productos que sean confiables y oportunos: la práctica de nuevas herramientas de gestión institucional, y, finalmente, un imprescindible sistema de rendición de cuentas.

\subsection{Marco legal de los sistemas administrativos de planeamiento estratégico y presupuesto público en Perú}

En aplicación de la Ley Orgánica del Poder Ejecutivo, Ley N²9158, se crearon los sistemas administrativos con la finalidad de promover la eficacia y eficiencia en el uso de los recursos asignados a las entidades de la administración pública estableciendo unidades de distinto nivel orgánico y funcional, normatividad de carácter técnico y legal y procesos. Asimismo, con el propósito de "establecer normas básicas sobre la Administración Financiera del Sector Público para su gestión integrada y eficiente, de manera intersistémica, en un contexto de sostenibilidad y responsabilidad fiscal" se promulgó el Decreto Legislativo $\mathrm{N}^{\circ}$ 1436. Esta disposición legal permitió reforzar, progresivamente, la unión de sinergias de los distintos sistemas de administración financiera del sector público, con la finalidad que los enunciados formulados como políticas de Estado permitan el impulso del país hacia una sociedad más igualitaria e inclusiva.

El Sistema Nacional de Planeamiento Estratégico, como ya ha sido señalado, fue creado mediante Decreto Legislativo $\mathrm{N}^{\circ} 1088$ y conforme al artículo 2 constituye un "conjunto articulado e integrado de órganos, subsistemas y relaciones funcionales con la finalidad de coordinar y viabilizar el proceso de planeamiento estratégico nacional a fin de promover y orientar el 
desarrollo armónico y sostenido del país". El CEPLAN fue constituido como órgano rector y orientador de dicho sistema.

La Directiva para la Actualización del Plan Estratégico de Desarrollo Nacional - (PEDN) definió los lineamientos para la actualización del PEDN en el marco del ciclo de planeamiento estratégico para la mejora continua. Según esta norma de carácter técnico, dicho ciclo está constituido por cuatro fases que esquemáticamente se visualizan en la Figura 3.

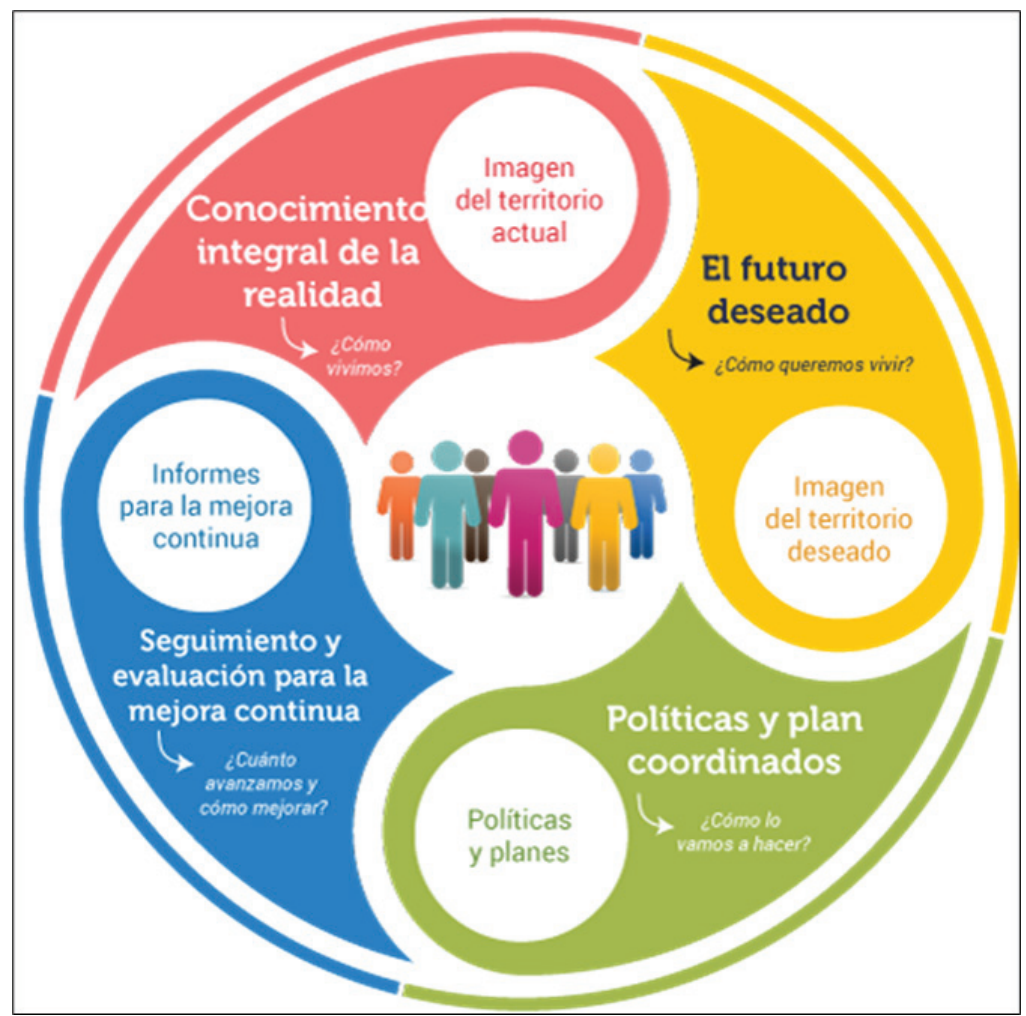

Figura 3. Fases del ciclo de planeamiento estratégico para la mejora continua. Fuente. Directiva № 001-2017-CEPLAN/PCD, Directiva para la Actualización del Plan Estratégico de Desarrollo Nacional.

Con relación al Sistema de Presupuesto, cabe señalar que conforme a las disposiciones generales del Decreto Legislativo $\mathrm{N}^{\circ} 1440$ : 
El Presupuesto del Sector Público está constituido por los créditos presupuestarios que representan el equilibrio entre la previsible evolución de los ingresos y los recursos a asignar de conformidad con las políticas públicas del gasto, estando prohibido incluir autorizaciones de gasto sin el financiamiento correspondiente. El Presupuesto del Sector Público tiene vigencia anual y coincide con el año calendario. Durante dicho periodo se afectan los ingresos que se recaudan y/o perciben dentro del año fiscal, cualquiera sea la fecha en que se hayan generado y se realizan las gestiones orientadas a la ejecución del gasto con cargo a los respectivos créditos presupuestarios.

El numeral 13.1 de la norma precitada define operacionalmente el presupuesto en los términos siguientes:

el presupuesto constituye el instrumento de gestión del Estado para el logro de resultados a favor de la población, a través de la prestación de servicios y logro de metas de coberturas con eficacia y eficiencia por parte de las Entidades. Asimismo, es la expresión cuantificada, conjunta y sistemática de los gastos a atender durante el año fiscal, por cada una de las Entidades que forman parte del Sector Público y refleja los ingresos que financian dichos gastos.

Por lo expuesto, el Sistema Nacional de Planeamiento Estratégico y el Sistema Nacional de Presupuesto Público son dos sistemas importantísimos que se constituyen en pilares fundamentales del modelo de gestión pública orientada a resultados, cuya armonización contribuye a que el logro de los resultados, establecidos en los planes estratégicos, orienten esfuerzos precisos, para el cierre de las brechas de infraestructura y de acceso a servicios priorizados por el Estado.

\subsection{Reseña histórica de los sistemas administrativos planea- miento estratégico y presupuesto público en Perú.}

Marcel et al. (2014) afirman que hacia la mitad del siglo XX "la planificación como ejercicio centralizado y estratégico asumió un rol central en la promoción del capitalismo de Estado". En este aspecto, un hecho de especial importancia para la incorporación y desarrollo del planeamiento en 
el sector público peruano fue la creación, en 1961, de la Alianza para el Progreso bajo el auspicio de los Estados Unidos de Norteamérica como un programa que permitiría impulsar el desarrollo de América del Sur y el Caribe. A este respecto Rojas $(2010$, p.96) cita parte del discurso pronunciado (Washington, 1961) por el entonces presidente Kennedy cuando anunció la creación de dicho programa:

El nivel de vida de cada familia americana irá en aumento, la educación básica estará disponible para todos, el hambre será una experiencia olvidada, ya habrá pasado la necesidad de una ayuda externa masiva y la mayoría de las naciones habrá entrado en un período de crecimiento autónomo y, aunque todavía habrá mucho por hacer, cada república americana dirigirá su propia revolución y esperanza y progreso.

Esta iniciativa del presidente norteamericano fue formalmente aceptada en la Reunión de Punta del Este (Uruguay, agosto de 1961). Como conclusión de esta reunión se emitió la Declaración a los Pueblos de América (Alianza para el Progreso, s/f, p.12), en el que las autoridades signatarias establecieron: "Los países de la América Latina formularán programas nacionales amplios y debidamente estudiados para el desarrollo de sus economías como las contribuciones de cada uno a la Alianza para el Progreso". Asimismo, se suscribió el documento al que se denominó la Carta de Punta del Este (1961, p.19) en el que se estableció que:

Los países latinoamericanos participantes convienen en implantar o en fortalecer sistemas para la preparación, ejecución y revisión periódica de los programas nacionales de desarrollo económico y social compatibles con los principios, objetivos y requisitos contenidos en este documento. Los países latinoamericanos participantes deberán formular, dentro de los próximos 18 meses, si fuere posible, programas de desarrollo a largo plazo.

Según Malpica et al. (2008), como consecuencia de estos acuerdos, mediante el Decreto Supremo № 49 de 3 de noviembre de 1961 se creó en la estructura del entonces Ministerio de Hacienda y Comercio, hoy Ministerio de Economía y Finanzas, la Oficina Central de Estudios y Programas. A pesar de haberse producido una interrupción en el orden democrático de Perú, debido a la toma del poder político por la Fuerza 
Armada el 17 de julio de 1962, el 19 de octubre de 1962, mediante el Decreto Ley $N^{\circ} 14220$, se creó el Sistema Nacional de Planificación del Desarrollo Económico y Social y se constituyó al Instituto Nacional de Planificación (INP) como entidad rectora de dicho sistema. En los considerandos del mencionado dispositivo legal se establecieron los propósitos de la creación del mencionado sistema: (i) "acelerar el mejoramiento de las condiciones de vida del pueblo peruano"; (ii) "aprovechar y estimular la iniciativa y la capacidad creadora de los distintos sectores de la población"; (iii) orientar y hacer "más eficaz la acción pública", acentuar y armonizar "los estímulos a la iniciativa privada"; (iv) "propender a una adecuada descentralización"; (v) necesidad "que los planes de desarrollo económico y social contengan metas de largo, mediano y corto plazo"; (vi) "que el presupuesto fiscal se convierta en instrumento fundamental del desarrollo económico y social”.

Según Cardó y otros (1989, p. 79):

La creación del INP y de la planificación sectorial se realiza en el marco de novedosas medidas. Entre ellas, debemos considerar: (i) la preparación del Primer Diagnóstico Económico y Social del Perú, (ii) la introducción, en 1963, del presupuesto por programas, (iii) la elaboración de los primeros programas de inversiones públicas 1964-65 y 1966, y (iv) un perfeccionamiento de los criterios de sectorialización y racionalización de la administración pública.

El marco teórico que sustentaba lo anteriormente descrito señalaba que el Estado era el promotor del desarrollo y la inversión, y se debía aplicar la sustitución de las importaciones. Desde 1968 a 1980, el país fue gobernado nuevamente por la Fuerza Armada. Pero, es de señalar que entre 1968 y 1975 que se desarrolló lo que se denominó la Primera Fase de la Revolución Peruana, a la planificación se le concedió especial importancia por cuanto fue considerada como herramienta de gobierno.

Posteriormente, en la década de los 80, según Marcel et al. (2014, p.315) "se dieron dos hechos que influyeron en el declive de la importancia de la planificación como instrumento técnico para orientar el desarrollo del país", a tal punto que la "reacción fue en algunos casos implacable e incluyó la eliminación de los Ministerios de Planificación y las agencias públicas de desarrollo". Uno de ellos fue el denominado Consenso de Washington 
y otro los graves desequilibrios fiscales que se presentaron en los diversos países de la región. Por ello es por lo que, según Cardó et al. (1989, p. 131) en el período comprendido entre los años 1975 y 1980, la planificación "pierde totalmente su importancia y se supedita a las decisiones del aparato económico-financiero".

Según Cáceres y Paredes (1991, p. 133), a fines del año 1989 “los indicios del profundo desequilibrio macroeconómico por el cual atravesaba el país [...] eran múltiples y estaban estrechamente interrelacionados". Dichos indicios fueron comentados en los términos siguientes: (i) "Inflación alta e inestable", siendo en el primer trimestre del año señalado de 7 800\% y como tasa de inflación anual de 2 775\%. (ii) "Recesión sostenida". (iii) "Desempleo creciente y bajos salarios reales". (iv) "Ingresos tributarios deprimidos y persistencia de déficit en el sector público". (v) "Desintermediación financiera". (vi) "Pérdida de reservas internacionales". Es evidente que, en el marco del desequilibrio macroeconómico muy resumidamente expuesto, el Sistema Nacional de Planificación perdió efectividad y la energía administrativa suficiente para proponer planes de desarrollo económico y social del país. Es por ello que, en 1992, por Decreto Ley $\mathrm{N}^{\circ}$ 25548, en el marco de la reestructuración del sector público, el INP fue disuelto y desactivado. Sus funciones fueron transferidas al MEF a excepción de los temas vinculados al medio ambiente y recursos naturales que correspondieron al Ministerio de Agricultura y los relacionados con la Cooperación Técnica Internacional al denominado Ministerio de la Presidencia, en funcionamiento en aquel entonces. A partir de esta decisión, la mayoría de las organizaciones estatales aparato comenzaron a utilizar la metodología del sector privado para la formulación de sus respectivos planes estratégicos. Es así como partieron del estudio interno de las entidades a fin de determinar sus fortalezas y debilidades y del estudio del entorno en que cada entidad se desenvolvía para establecer las oportunidades y amenazas; es decir se aplicó, entre otras técnicas, lo que se ha convenido en llamar el Análisis FODA.

Como se ha señalado anteriormente, con la institucionalización del Acuerdo Nacional, en el año 2002, se retomó la planificación y se le incorporó la característica de estratégica y mediante sendos dispositivos legales se crearon el Sistema Nacional de Planeamiento Estratégico - SINAPLAN y el Centro Nacional de Planificación Estratégico. 
Al realizar la revisión bibliográfica para el desarrollo de la investigación que ha dado origen a la presente publicación no se ha encontrado ninguna fuente que permita visualizar cómo se ha desenvuelto la práctica de la elaboración del presupuesto en el Perú a partir de su nacimiento a la vida republicana. Morón (1999, p.159) señaló que:

Los principios presupuestarios que con mayor recurrencia han sido asumidos en nuestros textos constitucionales han sido los de anualidad, anticipación, competencia, universalidad y el de garantía de pago de deudas del Estado. Sin embargo, en esta revisión histórica también podemos apreciar que algunos principios presupuestarios reiteradamente constitucionalizados por los constituyentes, en los últimos años han seguido camino inverso, perdiendo tal jerarquía y relativizándose hasta quedar librados a la legislación coyuntural. Tales son los principios de responsabilidad personal y solidaria de las autoridades por una indebida ejecución presupuestal y el de publicidad presupuestaria. Coincidentemente, ambos están referidos a la transparencia en la administración de los recursos públicos.

\section{Resultados y discusión}

\subsection{Datos de las variables.}

\subsubsection{Variable independiente $\left(X_{1}\right)$ : Plan Operativo Institucional (POI).}

Está relacionada con el cumplimiento de las metas físicas de la actividad operativa vinculada con la asistencia técnica y desarrollo de capacidades en metodología de planeamiento estratégico para la elaboración de documentos de gestión en los sectores del gobierno nacional plasmados en los POI aprobados durante el periodo de análisis.

Variable $\mathrm{X}_{1} \longrightarrow$ Actividad programada. Donde $\mathrm{X}_{1}=$ Actividad programada.

La tabla 2 hace referencia a las Actividades programadas vinculadas con la asistencia técnica y desarrollo de capacidades en meto- 
dología de planeamiento estratégico aprobadas en el Plan Operativo Institucional - POI.

\section{Tabla 2}

Actividades programadas aprobadas en el Plan Operativo Institucional - POI.

\begin{tabular}{|c|c|}
\hline Año fiscal & \multicolumn{1}{|c|}{ Actividad programada $^{7}$} \\
\hline 2009 & 4 \\
\hline 2010 & 1 \\
\hline 2011 & 1 \\
\hline 2012 & 3 \\
\hline 2013 & 1 \\
\hline 2014 & 3 \\
\hline 2015 & 15 \\
\hline 2016 & 6 \\
\hline 2017 & 45 \\
\hline 2018 & 40 \\
\hline
\end{tabular}

Fuente: Planes Operativos Institucionales del CEPLAN y SIAF ADMINISTRATIVO. Elaboración propia.

\subsubsection{Variable independiente (X2): Proyección de gastos (PG).}

Se encuentra vinculada al conjunto de previsiones de gastos que demandará la ejecución de las tareas a realizar a través de la asistencia técnica y desarrollo de capacidades de los sectores del gobierno nacional en un horizonte de corto plazo.

Para tal fin, se ha tomado como criterio una aproximación de gastos ejecutados, teniendo como referencia una línea base porcentual de la distribución del gasto del año fiscal 2009 (4,60\%); el cual, ha sido redistribuido en cada ejercicio fiscal, con las asignaciones presupuestarias aprobadas para la entidad en el período que ha comprendido la presente investigación. Ver Tabla 3.

La tabla 3 hace referencia a la Programación de gastos vinculada a la asistencia técnica y desarrollo de capacidades en metodología de planeamiento estratégico durante el período 2009-2018. 
Tabla 3

Programación de gastos durante el período 2009-2018.

\begin{tabular}{|c|c|c|c|}
\hline $\begin{array}{c}\text { Año } \\
\text { fiscal }\end{array}$ & $\begin{array}{c}\mathbf{P I M}^{\mathbf{8}} \\
\mathbf{X}_{\mathbf{0}}\end{array}$ & $\begin{array}{c}\text { Línea base de gasto } \\
\mathbf{X}_{\mathbf{1}}\end{array}$ & $\begin{array}{c}\text { Programación gastos estimados } \\
\mathbf{X}_{\mathbf{2}}=\mathbf{X}_{\mathbf{0}} \mathbf{X}_{\mathbf{1}}\end{array}$ \\
\hline 2009 & 3000000 & $4,60 \%$ & 137928 \\
\hline 2010 & 9000000 & $4,60 \%$ & 413784 \\
\hline 2011 & 10603650 & $4,60 \%$ & 457513 \\
\hline 2012 & 9961158 & $4,60 \%$ & 457974 \\
\hline 2013 & 15014200 & $4,60 \%$ & 690293 \\
\hline 2014 & 14395000 & $4,60 \%$ & 672661 \\
\hline 2015 & 14395000 & $4,60 \%$ & 661823 \\
\hline 2016 & 15669203 & $4,60 \%$ & 720407 \\
\hline 2017 & 15773305 & $4,60 \%$ & 725193 \\
\hline 2018 & 16647277 & $4,60 \%$ & 719399 \\
\hline
\end{tabular}

Fuente. Planes Operativos Institucionales del CEPLAN y SIAF ADMINISTRATIVO. Elaboración propia.

\subsubsection{Variable independiente (X): Planificación Estratégica (PE) - Proceso Presupuestario (PP)}

Esta variable está asociada a la articulación Plan-Presupuesto por cuanto la estructura de dichas variables está compuesta de manera agregada por las actividades programadas y la ejecución de gastos.

Variable X $\longrightarrow$ Articulación Plan - Presupuesto

$\mathrm{X}_{1}+\mathrm{X}_{2}=\mathrm{X}$

Donde:

$\mathrm{X} 1$ = Actividad programada

X2 = Programación de gastos

Como se puede apreciar, los valores dados para la variable X1 corresponden a las metas físicas de la actividad operativa vinculada a la asistencia técnica y desarrollo de capacidades en metodología de planeamiento estratégico para la elaboración de políticas y planes en los sectores del gobierno nacional que se traducen en los POI aprobados durante el periodo de análisis. Asimismo, los valores dados para la variable X2 están determinados por la proyección de gasto de las tareas a realizar relacionadas 
con la prestación de asistencia técnica e impulso de capacidades de los sectores del gobierno nacional. En la Tabla 4, se muestra la obtención de la variable X: Articulación Plan - Presupuesto en el periodo de evaluación 2009 - 2018, a través del cual se puede apreciar una tendencia creciente entre la actividad programada y la proyección de gastos.

Tabla 4

Datos de la variable independiente: Articulación Plan - Presupuesto del CEPLAN.

\begin{tabular}{|c|c|c|c|c|}
\hline $\begin{array}{c}\text { AÑO } \\
\text { FISCAL }\end{array}$ & $\begin{array}{l}\text { ACTIVIDAD PROGRAMADA (1) } \\
\text { X1 }\end{array}$ & $\begin{array}{c}\text { PROGRAMACIÓN GASTOS } \\
\text { X2 }\end{array}$ & $\begin{array}{c}\text { TOTAL X } \\
\mathrm{X}=\mathrm{X} 1+\mathrm{X} 2\end{array}$ & $\begin{array}{c}\text { TOTAL X } \\
\text { (En miles) }\end{array}$ \\
\hline 2009 & 4 & 137,928 & 137,932 & 137.93 \\
\hline 2010 & 1 & 413,784 & 413,785 & 413.79 \\
\hline 2011 & 1 & 487,513 & 487,514 & 487.51 \\
\hline 2012 & 3 & 457,974 & 457,977 & 457.98 \\
\hline 2013 & 1 & 690,293 & 690,294 & 690.29 \\
\hline 2014 & 3 & 672,661 & 672,664 & 672.66 \\
\hline 2015 & 15 & 661,825 & 661,840 & 661.84 \\
\hline 2016 & 6 & 720,407 & 720,413 & 720.41 \\
\hline 2017 & 45 & 725,193 & 725,238 & 725.24 \\
\hline 2018 & 40 & 719,399 & 719,439 & 719.44 \\
\hline
\end{tabular}

(1) meta fisica programda en el Plan Operativo Insticional del año fiscal respectivo.

Fuente. Planes Operativos Institucionales del CEPLAN y SIAF ADMINISTRATIVO. Elaboración propia.

Es preciso mencionar, que la variable articulación Plan - Presupuesto, corresponde a una agregación entre la actividad programada y la programación de gasto, para lo cual, se ha aproximado a la adición de ambos componentes numéricos, con la finalidad de ser la variable que se aproxime a la mencionada articulación.

\subsubsection{Variable dependiente (Y): Gestión Pública del CEPLAN - GPC}

Esta variable corresponde al indicador de desempeño de cada año fiscal obtenido del Sistema de Gestión Presupuestal del MEF, cuyo nivel de alcance proporciona resultados cuantitativos sobre la consecución de los logros de una determinada organización en relación con los objetivos esenciales y misionales.

Variable $\mathrm{Y} \longrightarrow$ Indicador de desempeño 
El indicador de desempeño corresponde a una ponderación de los objetivos propuesta por la entidad en el año fiscal respectivo, con la ejecución física y financiera del gasto realizado. Para tal fin, se ha revisado la información sobre la gestión en la unidad orgánica funcionalmente competente relacionada con la evaluación anual del presupuesto del CEPLAN durante el periodo analizado.

En la Tabla 5, se muestra la evolución de la variable Indicador de Desempeño en el periodo de evaluación 2009 - 2018; en dicho cuadro se puede apreciar, de manera general, niveles crecientes de cumplimiento en los logros alcanzados por la entidad.

Tabla 5
Datos de la variable Gestión Pública $(Y)$.
Indicador de Desempeño
\begin{tabular}{|c|c|}
\hline AÑo & VALOR DE LA VARIABLE Y \\
\hline 2009 & $90 \%$ \\
\hline 2010 & $91 \%$ \\
\hline 2011 & $95 \%$ \\
\hline 2012 & $98 \%$ \\
\hline 2013 & $99 \%$ \\
\hline 2014 & $110 \%$ \\
\hline 2015 & $103 \%$ \\
\hline 2016 & $108 \%$ \\
\hline 2017 & $110 \%$ \\
\hline 2018 & $120 \%$ \\
\hline
\end{tabular}

Fuente. Documentos de gestión del CEPLAN. Elaboración propia.

Con la obtención de las variables precitadas se procedió al desarrollo de un modelo econométrico que tuvo por finalidad validar las hipótesis establecidas para el desarrollo del trabajo de investigación.

\subsection{Análisis de regresión (Prueba de Hipótesis)}

El modelo econométrico utilizado es el modelo de regresión lineal; el cual, permite explicar, a partir de una muestra representativa, la relación que existe entre una variable dependiente y una variable independiente. Dicha relación se muestra en el siguiente patrón lineal:

$$
Y=c+b * X+\mu
$$


Donde:

Y: Variable dependiente

c y b: Parámetros del modelo

$X$ : Variable independiente

$\mu$ : Perturbación o error aleatorio del modelo

Dicha estructura del modelo de regresión lineal puede estar dividida en dos grupos: el primero contiene una variable explicativa y el segundo incluye un conjunto amplio de factores no controlados que para fines del modelo se encuentran contemplados en la variable $\mu$.

Asimismo, el parámetro c es la ordenada en el origen; es decir, es la altura a la que la recta corta a la variable $Y$ denominada término independiente. El parámetro b, también denominado pendiente, es la inclinación de la recta; es decir, es el incremento que se produce en la variable Y, cuando la variable $\mathrm{X}$ disminuye en una unidad. En ese sentido, ambos parámetros (c y b) del modelo permiten reproducir la recta del modelo y describir con ella la relación existente entre las dos variables.

Es preciso mencionar, que el objetivo principal del modelo de regresión lineal es la determinación o estimación de los parámetros c y b a partir de una muestra dada; para tal fin, se buscar contrastar que los errores aleatorios del modelo cumplan los siguientes requisitos:

- La media de los errores $\mu$ del modelo han de ser cero. $E(\mu)=0$

- La varianza de $\mu$ es constante para cualquier valor de x. $\operatorname{Var}\left(\frac{\mu}{X}\right)=x=\partial^{2}$

- La distribución $\mu$ es normal, de media 0 y desviación $\partial$.

- Los errores asociados a los valores de Y son independientes unos de otros.

Para tal fin, se ha hecho uso de un paquete informático estadístico utilizado principalmente en el campo de la economía; tal herramienta ha permitido la estimación, resolución y usos de modelos econométricos de distinta naturaleza mediante la aplicación de una amplia gama de 
procedimientos. El nombre de dicho instrumento es Econometric Views (Eviews). A continuación, se contrastará la Hipótesis General (HG); para lo cual, se han ingresado los datos obtenidos de cada variable en el aplicativo Eviews lo que ha permitido obtener los resultados siguientes:

Estimation C:

=ニニニニニニニニニニニニニニニニニニニニニニニ=

LS GPC C DES

Estimation Equation:

ニニニニニニニニニニニニニニニニニニニニニニニニニ

$\mathrm{GPC}=\mathrm{C}(1)+\mathrm{C}(2) * \mathrm{DES}$

Substituted Coefficients:

=ニニニニニニニニニニニニニニニニニニニニニニニ=

$\mathrm{GPC}=0.796455858073+0.000400106455018 * \mathrm{DES}$

Los resultados del presente modelo econométrico, obtenidos en el desarrollo del programa Eviews para una muestra de 10 observaciones (2009-2018) de las variables Gestión Pública y Planeamiento Estratégico y Proceso Presupuestario se presentan en la Tabla 6.

Tabla 6

Resultados del modelo de regresión lineal - Hipótesis General

Dependent Variable: GPC

Method: Least Squares

Date: 02/13/18 Time: 10:51

Sample: 20092018

Included observations: 10

\begin{tabular}{|c|c|c|c|c|}
\hline Variable & Coefficient & Std. Error & t-Statistic & Prob. \\
\hline $\mathrm{C}$ & 0.796456 & 0.062692 & 12.70428 & 0.0000 \\
\hline DES & 0.000400 & 0.000105 & 3.811790 & 0.0051 \\
\hline R-squared & 0.644914 & Mean dependent var & & 1.024000 \\
\hline Adjusted R-squared & 0.600528 & S.D. dependent var & & 0.095824 \\
\hline S.E. of regression & 0.060564 & Akaike info criterion & & -2.593364 \\
\hline Sum squared resid & 0.029344 & Schwarz criterion & & -2.532847 \\
\hline Log likelihood & 14.96682 & Hannan-Quinn criter. & & -2.659751 \\
\hline F-statistic & 14.52974 & Durbin-Watson stat & & 1.647000 \\
\hline Prob(F-statistic) & 0.005150 & & & \\
\hline
\end{tabular}

Fuente: Elaboración propia. 
Asimismo, se contrastó la Hipótesis Específica (HE1): El Plan Operativo Institucional (POI) ha incidido en la gestión del CEPLAN 2009-2018. Para la cual se han ingresado los datos obtenidos de cada variable en el aplicativo Eviews lo que ha permitido obtener los resultados siguientes:

Estimation Command:

=ニニニニニニニニニニニニニニニニニニニニニニニ=

LS Y C X1

Estimation Equation:

=ニニニニニニニニニニニニニニニニニニニニニニニ=

$\mathrm{Y}=\mathrm{C}(1)+\mathrm{C}(2)^{*} \mathrm{X} 1$

Substituted Coefficients:

ニニニニニニニニニニニニニニニニニニニニニニニニニ

$\mathrm{Y}=0.97527783318+0.00409429973274 * X 1$

Los resultados del modelo econométrico obtenidos en el desarrollo del programa Eviews para una muestra de 10 observaciones (20092018) de las variables Gestión Pública y Plan Operativo Institucional se presentan en la Tabla 7.

Tabla 7

Resultados del modelo de regresión lineal - Hipótesis Específica 1

Dependent Variable: Y

Method: Least Squares

Date: 10/14/19 Time: 17:46

Sample: 20092018

Included observations: 10

\begin{tabular}{lcccr}
\hline \multicolumn{1}{c}{ Variable } & Coefficient & Std. Error & t-Statistic & Prob. \\
\hline C & 0.975278 & 0.028187 & 34.60059 & 0.0000 \\
X1 & 0.004094 & 0.001423 & 2.877027 & 0.0206 \\
\hline R-squared & 0.508518 & Mean dependent var & 1.024000 \\
Adjusted R-squared & 0.447082 & S.D. dependent var & 0.095824 \\
S.E. of regression & 0.071253 & Akaike info criterion & -2.268299 \\
Sum squared resid & 0.040616 & Schwarz criterion & -2.207782 \\
Log likelihood & 13.34149 & Hannan-Quinn criter. & -2.334686 \\
F-statistic & 8.277286 & Durbin-Watson stat & 1.699496 \\
Prob(F-statistic) & 0.020605 & & & \\
\hline
\end{tabular}

Fuente: Elaboración propia. 
Asimismo, se contrastó la Hipótesis Específica (HE2): La programación de gastos ha incidido en la gestión del CEPLAN 2009-2018. Para la cual se han ingresado los datos obtenidos de cada variable en el aplicativo Eviews lo que ha permitido obtener los resultados siguientes:

Estimation Command:

=ニニニニニニニニニニニニニニニニニニニニニニ=

LS Y C X2

Estimation Equation:

ニニニニニニニニニニニニニニニニニニニニニニニニニ

$\mathrm{Y}=\mathrm{C}(1)+\mathrm{C}(2) * \mathrm{X} 2$

Substituted Coefficients:

=ニニニニニニニニニニニニニニニニニニニニニニニ=

$\mathrm{Y}=0.796460259196+4.00106666168 \mathrm{e}-07 * \mathrm{X} 2$

Los resultados del modelo econométrico para una muestra de 10 observaciones (2009-2018) de las variables Gestión Pública y Programación de Gastos se presentan en la Tabla 8.

Tabla 8

Resultados del modelo de regresión lineal - Hipótesis Específica 2

Dependent Variable: Y

Method: Least Squares

Date: 10/14/19 Time: 17:56

Sample: 20092018

Included observations: 10

\begin{tabular}{|c|c|c|c|c|}
\hline Variable & Coefficient & Std. Error & t-Statistic & Prob. \\
\hline $\mathrm{C}$ & 0.796460 & 0.062697 & 12.70327 & 0.0000 \\
\hline $\mathrm{X} 2$ & $4.00 \mathrm{E}-07$ & $1.05 \mathrm{E}-07$ & 3.811386 & 0.0052 \\
\hline R-squared & 0.644865 & \multicolumn{2}{|l|}{ Mean dependent var } & 1.024000 \\
\hline Adjusted R-squared & 0.600473 & \multicolumn{2}{|l|}{ S.D. dependent var } & 0.095824 \\
\hline S.E. of regression & 0.060568 & \multicolumn{2}{|l|}{ Akaike info criterion } & -2.593227 \\
\hline Sum squared resid & 0.029348 & \multicolumn{2}{|l|}{ Schwarz criterion } & -2.532710 \\
\hline Log likelihood & 14.96614 & \multicolumn{2}{|l|}{ Hannan-Quinn criter. } & -2.659614 \\
\hline F-statistic & 14.52666 & \multicolumn{2}{|l|}{ Durbin-Watson stat } & 1.646767 \\
\hline Prob(F-statistic) & 0.005152 & & & \\
\hline
\end{tabular}

Fuente: Elaboración propia. 
Cabe señalar que se han utilizado medidas estadísticas como Evaluación del coeficiente de regresión individual - Distribución t de Student que ha permitido probar si los coeficientes de regresión individualmente son estadísticamente diferentes a cero. Se realizó una prueba de hipótesis $\left(H_{0}: B_{1}=0 ; H_{1}: B_{1} \neq 0\right)$, cuyo grado de significancia es usado frecuentemente por el valor del 0,05. El Coeficiente de Determinación o R cuadrado $\left(\mathrm{R}^{2}\right)$ que indica el grado de ajuste de la recta de regresión muestral con los datos. También se puede decir que es el porcentaje de variación muestral de la variable dependiente explicada por la variable independiente. Si $\mathrm{R}^{2}$ está próximo a cero, esto implica que el ajuste no es bueno. En otras palabras, hay muy poca alteración entre la variable dependiente y la variable independiente. Por lo general, en muchos modelos econométricos se obtiene un $\mathrm{R}^{2}$ elevado cuando se están utilizando datos de series temporales, pero que también puede ser relativamente bajo debido a la poca información cuantitativa del modelo, pero esto no significa que el modelo ajustado sea erróneo. El Coeficiente de correlación Durbin Watson - DW que posibilitar detectar la correlación serial; puesto que permite comprobar si la perturbación se encuentra autocorrelacionada (la perturbación relacionada entre observaciones no debería estar vinculada por la perturbación). Los valores del estadístico DW se encuentran en un rango comprendido entre 0 y 4. Si los niveles de decisión se estiman, en valores cercanos a 2, entonces no se rechaza la hipótesis nula (autocorrelación es igual a cero); por otro lado, para valores distanciados de 2 , se rechaza la hipótesis nula (autocorrelación se iguala a cero).

\subsection{Presentación de resultados.}

\subsubsection{Resultados de la Hipótesis General.}

- El T estadístico de la variable DES tiene un valor de 3,8, lo que comparado con el valor estadístico de la prueba T de Student con $(7 ; 0,05)=(4,03)$, permite corroborar la hipótesis nula; lo cual, demuestra que es significativo y sí tiene relevancia en el desarrollo del modelo presentado. Asimismo, se logra contrastar con el valor Prob, a través del cual la variable DES es menor al nivel predeterminado 0,05 .

- $\quad$ El R ${ }^{2}$ presenta un nivel del 64,5\%, el cual es relativamente bueno; tomando en consideración el intervalo de datos acotados (2009- 
2018). Esto significa que el $64,5 \%$ de la desarticulación de la planificación estratégica y la programación de gastos influyen en la Gestión Pública del CEPLAN.

- El DW es de 1,65, lo cual se encuentra cercano a 2, por lo tanto, el modelo es bastante confiable. Las perturbaciones del modelo no presentan algún tipo de dependencia en cuanto al orden de obtención, cumpliéndose con las condiciones del modelo de regresión lineal.

\subsubsection{Resultados de la Hipótesis Específica 1.}

- El T estadístico de la variable X1 tiene un valor de 2,8, lo que comparado con el valor estadístico de la prueba T de Student permite corroborar la hipótesis nula; ello demuestra que la mencionada variable es altamente importante en el desarrollo del modelo y confirma que tiene importancia en el modelo econométrico propuesto.

- El R2 es del 50,8\%, lo cual es relativamente bueno; tomando en consideración el intervalo de datos acotados (2009-2018).

- El DW es de 1,69, lo cual se encuentra cercano a 2, por lo tanto, el desarrollo del modelo es bastante fiable.

\subsubsection{Resultados de la Hipótesis Específica 2.}

- El T estadístico de la variable X2 tiene un valor de 3,8, lo que comparado con el valor estadístico de la prueba T de Student, permite corroborar la hipótesis nula; ello demuestra que la mencionada variable es altamente importante en el desarrollo del modelo y sí tiene importancia en el modelo de regresión.

- $\quad$ El R2 es del 64,4\%, lo cual es relativamente bueno; tomando en consideración el intervalo de datos acotados (2009-2018).

- $\quad$ El DW es de 1,65, lo cual que se encuentra cercano a 2, por lo tanto, el desarrollo del modelo es bastante fiable.

A partir de los análisis matemáticos realizados sobre la hipótesis general y las hipótesis específicas es permitido corroborar que la desarticulación 
entre la planificación estratégica y la programación de gastos ha influido negativamente sobre la gestión pública del CEPLAN en el periodo 2009-2018.

\subsection{Discusión}

En el marco de lo establecido en el artículo 44 de la Constitución Política del Perú expuesto en el marco teórico del presente artículo se señaló que al Estado le corresponde asumir el cumplimiento de deberes primordiales con relación a la población; para el cumplimiento de esos deberes dispone de instituciones y organismos que integran lo que se denomina la Administración Pública, los mismos que desarrollan diversas acciones que constituyen los servicios públicos.

En esta perspectiva, y dentro de las funciones administrativas que desempeña el Estado, existe una relacionada con el desarrollo de acciones de orientación y coordinación; entre estas, hay una de especial y vital importancia como las relacionadas con el planeamiento estratégico porque ello permite establecer, en un horizonte temporal de corto, mediano y largo plazo, las acciones que se prevén desarrollar para alcanzar la visión, objetivos priorizados y metas del desarrollo económico y social de la nación.

Para desarrollar la "planificación estratégica como instrumento técnico de gobierno y gestión para el desarrollo armónico y sostenido del país y el fortalecimiento de la gobernabilidad democrática en el marco del Estado constitucional de derecho", se crearon el Sistema Nacional de Planeamiento Estratégico y el Centro Nacional de Planeamiento Estratégico (artículo $1^{\circ}$ del Decreto Legislativo $\mathrm{N}^{\circ} 1088$ ).

De la revisión bibliográfica realizada no se ha encontrado ninguna investigación que haya abordado, desde el punto de vista de la ciencia de la economía y de la econometría, como una de sus ramas especializadas, la vinculación entre planificación estratégica y sistema presupuestario y la incidencia de estos en la gestión de alguna entidad pública, en general, y del CEPLAN, en particular. Es preciso recordar que al conjunto de acciones que realiza cada institución u organismo público para la materialización o concreción de su visión, logro de sus propios objetivos y metas mediante la ejecución de planes y programas se le denomina gestión pública.

Se estima necesario comentar que los resultados obtenidos en la presente investigación son congruentes con una, aunque no aleatoriamente 
colocada en primer lugar, de las deficiencias de la gestión pública en Perú establecidas en el documento denominado Política Nacional de Modernización de la Gestión Pública al 2021 aprobado por Decreto Supremo N ${ }^{\circ}$ 003-2013-PCM. La deficiencia es descrita en los términos siguientes: "Ausencia de un sistema eficiente de planeamiento y problemas de articulación con el sistema de presupuesto público" (p. 12) y llega a establecer casi a modo de conclusión que dicha ausencia "no logra utilizar el planeamiento como herramienta efectiva de gestión y no articula el plan y el presupuesto público" (p. 12). En consecuencia, dados los resultados obtenidos y desde la óptica personal del investigador, esa ausencia o desvinculación incide en la conducción de las entidades públicas.

Los resultados obtenidos son congruentes con las conclusiones establecidas por Neyra (2012, p.124):

(i) la Planificación y el Presupuesto Público integrados influyen positivamente en la gestión pública de la Defensoría del Pueblo. (ii) El proceso de planificación con estrategias definidas y una programación especificada y direccionada a alcanzar los objetivos esperados y los recursos presupuestales que permitan llevarla a cabo, influenciará favorablemente en la gestión de la Defensoría del Pueblo.

Asimismo, los resultados obtenidos son coherentes con lo establecido por la investigadora Tanaka (2011, p.126) "en el Ministerio de Salud se ha observado una débil articulación del planeamiento con el presupuesto desde una perspectiva de resultados".

\section{Conclusiones}

Los resultados estadísticos obtenidos han permitido comprobar la hipótesis general formulada al inicio del desarrollo del presente trabajo de investigación; es decir, la desarticulación que ha tenido el sistema de planeamiento estratégico con la programación de gastos, entre los años 2009-2018, ha incidido negativamente en la gestión pública del CEPLAN. Esto se sostiene en: el grado de confianza equivalente al 95\% que tienen las variables empleadas (Gestión Pública y Desarticulación del Planeamiento Estratégico y Proceso Presupuestario), el Coeficiente de determinación $\left(\mathrm{R}^{2}\right)$ del modelo que alcanza una representatividad del 64,5\%, la 
cual es adecuada, tomando en consideración el intervalo de datos acotados y el coeficiente de correlación DW es del 1,65 (cercano a 2), lo que aseguraría confiabilidad al modelo.

Se comprueban, también, la primera y la segunda hipótesis específicas; dado que la desarticulación entre el Plan Operativo Institucional (POI) y la programación de gastos han incidido negativamente en la gestión pública del CEPLAN. La vinculación de la variable planeamiento estratégico y programación de gastos ha ejercido notable influencia en la gestión pública del CEPLAN.

Se ha priorizado el análisis de una de las actividades operativas del CEPLAN "Asistencia técnica para la elaboración de políticas y planes en sectores" que se inscribe en la acción estratégica de la entidad "promover, orientar y asesorar en la elaboración de políticas y planes de acuerdo con el ordenamiento del Estado". En el periodo en estudio, en esta actividad se ha obtenido un nivel promedio de ejecución de cumplimiento (metas físicas) del 78\%, lo que permite señalar que la programación de gastos para su ejecución ha sido prácticamente nula. No ha habido, entre otros temas, una programación presupuestaria adecuada.

La desarticulación que presentan las actividades operativas vinculantes con la acción estratégica "Asistencia técnica en la formulación de planes estratégicos" con el presupuesto proyectado ha tenido como consecuencia que no se logren los objetivos institucionales de la entidad (medido de manera agregada a través de los indicadores de desempeño).

\section{Recomendaciones}

Considerando que los resultados obtenidos han evidenciado la hipótesis general que ha orientado el desarrollo de la investigación, se recomienda que a través de un trabajo conjunto del Ministerio de Economía y Finanzas (MEF) con el CEPLAN se diseñen procedimientos técnicos y metodológicos con el propósito de optimizar la articulación entre dichos sistemas. Esto permitirá al CEPLAN aumentar el alcance de la asistencia técnica y desarrollar capacidades técnicas y metodológicas en planeamiento estratégico para la elaboración de importantes documentos de gestión institucional 
como son los planes estratégicos institucionales y los planes operativos institucionales.

Se recomienda que el MEF otorgue mayores recursos presupuestarios al CEPLAN a fin de que este consolide, a nivel nacional, la rectoría en la conducción del Sistema Nacional de Planeamiento Estratégico del Sector Público.

Se recomienda que durante el proceso de la programación presupuestaria cuya conducción en los tres niveles de gobierno le corresponde al MEF se priorice, entre otras variables, el grado de cumplimiento de los objetivos institucionales de cada entidad; de tal forma, que el accionar de cada una de ellas contribuya al logro de las metas nacionales previstas en el PEDN.

Implementar, a través del CEPLAN y el MEF, un sistema único integrado de costeo a nivel de gasto detallado; a fin, que pueda ser utilizado, como insumo principal, para la articulación entre el Sistema Nacional de Planeamiento Estratégico y el Proceso Presupuestario del Sector Público del Perú.

Se recomienda continuar con la política de Estado relacionada con la modernización de todos los sistemas administrativos con un enfoque intrasistémico, a fin de optimizar el desempeño de las entidades públicas, el rendimiento y la eficiencia de todo el aparato estatal en beneficio de la sociedad peruana.

Por todo lo expuesto, se puede afirmar que un proceso de planificación con acciones estratégicas claramente establecidas y una programación de gasto específica y centrada a conseguir los objetivos establecidos permitirá mejorar favorablemente la gestión pública del CEPLAN.

\section{Referencias Bibliográficas}

Alvarado, B. y Morón, E. (2008). Perú, hacia un presupuesto por resultados: afianzando la transparencia y rendición de cuentas. Centro de Investigación de la Universidad del Pacífico. 196p.

Armijo, M. (2009). Manual de planificación estratégica e indicadores de desempeño en el sector público. Instituto Latinoamericano de Planificación Económica y Social (ILPES)/Comisión Económica para América Latina y el Caribe (CEPAL). 103p. 
Cáceres, A. y Paredes, C. (1991). Diagnóstico de la situación económica a fines de 1989. En C. Paredes y J. Sachs (Eds.), Estabilización y crecimiento en el Perú. Perú, Grupo de Análisis para el Desarrollo (GRADE). p.132-154.

Decreto Legislativo № 1088 de 27 de junio de 2008. Ley del Sistema Nacional de Planeamiento Estratégico y del Centro Nacional de Planeamiento Estratégico.

Decreto Legislativo $\mathrm{N}^{\circ}$ 1436. Decreto Legislativo Marco de la Administración Financiera del Sector Público. Publicada el 16 de setiembre de 2018.

Decreto Legislativo $\mathrm{N}^{\circ}$ 1440. Decreto Legislativo del Sistema Nacional de Presupuesto Público. Publicado el 16 de setiembre de 2018.

Centro Nacional de Planeamiento Estratégico (CEPLAN). (2017). Directiva No 001-2017-CEPLAN/PCD. Directiva para la actualización del Plan Estratégico de Desarrollo Nacional. Publicada el 3 de mayo de 2017.

Decreto Ley № 14220. Creando un sistema nacional de planificación del desarrollo económico y social del país. Publicada el 20 de octubre de 1962.

Decreto Ley $\mathrm{N}^{\circ}$ 25548. Crean la comisión de disolución y transferencia del Instituto Nacional de Planificación-INP. Publicado el 10 de junio de 1992.

Granados, S.; Larraín, F. y Rodríguez, J. (2009). Planificación y presupuesto como herramientas de política pública. En Consorcio para la Reforma del Estado (Eds.), Un mejor Estado para Chile. Chile. p.561-587.

Guerra-García, G. (2001). Hacia un sistema de planificación estratégica gubernamental para el Perú.

Hernández, R.; Fernández, C. y Baptista, P. (2010). Metodología de la investigación. México: McGraw-Hill. 613p.

Ley № 28522. Ley del sistema nacional de planeamiento estratégico y del centro nacional de planeamiento estratégico (CEPLAN). Publicada el 24 de mayo de 2005

Ley № 28927. Ley de Presupuesto del Sector Público para el Año Fiscal 2007. Publicada el 12 de diciembre de 2006.

Ley N²9158. Ley Orgánica del Poder Ejecutivo. Publicada el 20 de diciembre de 2007.

Malpica, C.; De la Cruz, L.; Montoya, M. y Velasco, O. (2008). El Decreto Legislativo 1008, Ley del sistema nacional de planeamiento estratégico y del Centro Nacional de Planeamiento Estratégico: análisis y perspectivas. Documento Interno de Trabajo (segunda versión).

Martner, G. (1978). Planificación y presupuesto por programas. México, Ed. Siglo XXI. 551p. 
Moreno, A. (1994). La reforma administrativa en los Estados Unidos. El plan del presidente Clinton. Revista de Administración Pública, 134, p. 521-540.

Marcel, M.; Guzmán, M. y Sanginés, M. (2014). Presupuestos para el desarrollo de América Latina. Banco Interamericano de Desarrollo. Estados Unidos de Norteamérica.

Neyra, M. (2012). El planeamiento y el presupuesto público y su influencia en la gestión pública. Caso Defensoría del Pueblo, periodo 2000-2010. (Tesis de Maestría inédita). Universidad Nacional de Ingeniería, Lima. 149p.

Organización de las Naciones Unidas para la Educación, la Ciencia y la Cultura (UNESCO). (s/f). Principios del planeamiento de la educación. 42p.

Prieto, M. (2012). Influencia de la gestión del presupuesto por resultados en la calidad del gasto en las municipalidades del Perú (2006-2010). Caso: Lima, Junín y Ancash. (Tesis de doctorado inédita). Universidad de San Martín de Porres, Lima. 141p.

Proyecto USAID/Perú ProDescentralización. (2009). Acercándonos al presupuesto por resultados. Guía informativa. Lima. 24p.

Shack, N. (2008). Intentando caracterizar la articulación entre el plan y el presupuesto. Algunas experiencias en América Latina. Banco Interamericano de Desarrollo - BID. 54p.

Shack. N. (2014). La articulación entre el plan y el presupuesto: un tema recurrente en el trabajo del ILPES en la región. En J. Máttary D. Perrotti. (Eds.) Planificación, prospectiva y gestión pública. Reflexiones para la agenda de desarrollo. Chile, Comisión Económica para América Latina y el Caribe [CEPAL]. p.139-157.

Tanaka, E. (2011). Influencia del presupuesto por resultados en la Gestión Financiera Presupuestal del Ministerio de Salud. (Tesis de maestría inédita). Universidad Nacional Mayor de San Marcos. Lima. 139p.

Tavares, M. y Berretta, N. (2006). Sistemas de planificación estratégica e innovaciones presupuestarias. Informe preparado para el Banco Interamericano de Desarrollo Programa de ejecución del Pilar Externo del Plan de Acción a Mediano Plazo para la Efectividad en el Desarrollo (PRODEV). 86p.

Tavares, M. y Berretta, N. (2009). Sistemas de planificación estratégica e innovaciones presupuestarias. En Banco Interamericano de Desarrollo (Eds.), Efectividad en el desarrollo y gestión presupuestaria por resultados. Documentos presentados en las reuniones de la Red de Gestión y Transparencia de la Política Pública del Diálogo Regional de Política. (p.17-45). 


\section{Notas al final}

1 El presente artículo corresponde a la modalidad de artículo científico. La investigación original fue realizada por el autor para sustentar su tesis de grado de Magíster en Economía con mención en Gestión y Políticas Públicas. La tesis llevó el título: "La desarticulación entre el sistema de planeamiento estratégico y la programación presupuestaria y su incidencia en la gestión pública del CEPLAN: 2009-2018”.

2 Economista de la Universidad Nacional Mayor de San Marcos, con estudios de Maestría en Economía con mención en Gestión y Políticas Públicas en la Universidad Nacional Mayor de San Marcos, Lima, Perú. Especialista en Planeamiento y Presupuesto de la Oficina de Planeamiento y Presupuesto de la Autoridad para la Reconstrucción con Cambios -ARCC, Jirón de la Unión 264, Lima, Lima. E-mail: marcos_galloso@hotmail.com

3 Economista de la UNMSM. Magister en Docencia Universitaria. Universidad Enrique Guzmán y Valle. Profesor Principal. Facultad de Ciencias Económicas. Universidad Nacional Mayor de San Marcos. Lima. E-mail: jospino@unmsm.edu.pe

4 "Espacio tripartito de diálogo y construcción de consensos, conformado por el Gobierno en sus tres niveles y las principales instituciones políticas y sociales del país". Fuente: Página web del Acuerdo Nacional.

5 “Corresponden a los ingresos provenientes de la recaudación tributaria y otros conceptos". Fuente: Clasificador de fuentes de financiamiento. Año Fiscal 2019. Anexo 4.

6 PPBS: planning, programming, budgeting and system.

7 Meta física programada en el respectivo POI.

8 PIM: Presupuesto Institucional Modificado. 